\section{Fashion Film and Genre Ecology}

\section{Synne Skjulstad}

Westerdals: Oslo School of Arts, Communication and Technology

synne@westerdals.no

\section{ABSTRACT}

We analyse the challenges and changing character, production and consumption of the emerging genre fashion film through a genre as ecology approach. This approach accounts for the complexity of various rhetorical practices used within the creative industries, such as fashion. We find that digital mediation compels genre innovation in networked cultures in the mediation of fashion. We examine three fashion films to ascertain how they function as cultural production within weband mobile-based communication and networked articulations. These need to be understood as part of distributed, polyvocal and multimodally mediated digital branding and advertising strategies that have largely not been addressed as genre by media and communication studies. Genre ecology is proposed as an addition to typological and developmental models of (media) genre innovation.
Andrew Morrison

Oslo School of Architecture and Design (AHO)

andrew.morrison@aho.no

\section{Keywords}

Genre Ecology; Fashion mediation; Genre Innovation; Branding

\section{INTRODUCTION}

"Fashion film" describes the emergence of short digital films on, with and about aspects of fashion, from amateur productions to professional ones. These films transgress categories and genres and contexts of cultural production and uptake. They are woven into a wider network of mediated articulations of fashion, which may be approached as cultural innovations in terms of both media and genre ecology. By examining fashion film in such a perspective, we argue that not only the films, but also the mesh of platforms, contexts and expressions central to mediation of fashion in contemporary branding and advertising might be understood more fully. Such an approach makes it possible to see fashion film as not just adding extra layers of
The Journal of Media Innovations 3.2 (2016), 20-41.

DOI: http://dx.doi.org/10.5617/jmi.v3i2.2522

(c) Synne Skjulstad and David Morrison 2016. meaning to a fashion brand; what may be appreciated in this view is that genre is realised through mediated social action (Shepherd \& Miller, 2004) that contributes to mediational innovation transgressing more established genre boundaries.

Previous approaches to genre analysis, emerging later than those in literary studies, have been predominantly textual and linguistically framed, whether in film studies or applied linguistics. They have explored textual practices, typologies and contexts of meaning production. A recent edited collection (Artemeva \& Freedman 2015) looking at genre studies across the globe from within writing, rhetoric and language studies argues that we need to look beyond three main Anglophone traditions concerning genre analysis. These were proposed by Sunny Hyon (1996): English for Specific Purposes, North American rhetoric approaches now called Rhetorical Genre Studies, and the Sydney school of genre studies framed in Systemic Functional Lin- 
guistics. This categorisation has been widely discussed. Carolyn Miller's notion of genre as social action (1984) may be seen as a common thread. However, as we show, genre may be approached less about following definitional prescriptions and pedagogical patterns for textual reproduction. It may also be understood performatively, that is as cultural production by way of motivated articulation that in communication design terms reaches towards new expression and modes of articulation. As Miller argues (this volume) these may be analysed by sets of components or essences or as evolutionary but also in a "third way": for us this way also differs somewhat from the three language located approaches to genre studies originating in applied linguistics. As we argue below, a genre ecology view is interdisciplinary, and in terms of media innovations, it is multimodal and while emergent and evolutionary, this view modifies both earlier notions of media ecology and genre as social action.

Recent work has motivated for a multimodal and discursive approach to mediated communication, as composition, through co-creation and performative enactment, whether in terms of strategic or directive, poetic or performative articulation (e.g. Morrison, 2010). In such views, genre may be understood also as a broad set of discursive moves, mediationally articulated, increasingly connected to digitally distributed communication that is no longer possible to process or analyse in terms of textual forms, contextual detail or communicative intent as earlier structuralist notions of genre attempted. A genre ecology approach enables a dynamic view of the multimodal rhetorics that currently mediate digital branding and advertising through fashion film. Extending the notion of genre to include ecology enables us to theorise how fashion film oscillates between conservative and the more playful and artistic outside of reductive notions of the scope or breadth of a narrowly demarcated genre. In investigating fashion film as part of a genre ecology, we may not only gain insight into how fashion is mediated via and across moving images online; such a framing may also inform further inquiry into how contemporary persuasive media practices in the creative industries unfold in and across digitally linked platforms and genres.

A genre ecology view thus enables us to incorporate a wider topography of related mediated textual expressions in our understanding of fashion film as a genre that is distributed and realised through digitally mediated social action (Miller \& Shepherd, 2004) but that is also emergent and developmental, slippery and transgressive as this is its communicative status. This is precisely because fashion film does not aim to conform to a structuralist set of genre rules and characteristics or to a mode of contextual genre realisation. Fashion film is understandable by virtue of its being a persuasive and rhetorical articulation that emerges from within a creative industry innovation within a mediated ecology of genre. Such a view on genre opens out communicative possibility by type while it conveys genre rhetorically, and especially dispositionally. It does so through poetic and discursive performance that is realised contextually. Fashion film is articulated temporally and mediationally in an age of web and social media, but also through uptake and is thus ecologically complex and fluid communicatively. It is not only realised as synchronic form or diachronically. As Anne Freadman (2015 Kindle edition) argues, "Genre is destabilised by uptake even as it asserts its powers. Trapped out as a theory that pins down language use, genre theory is like a rabbit trap, designed to catch its quarry. But nimble, fast-talking rabbits been known to get away." Fashion is notoriously fickle; our analysis follows a selection of nimble or dynamic media in fashion film online. However, rather than attempting to definitively seize it analytically, we invite readers to also access the web based productions 
themselves and to experience the mesh of mediated fashion film in an ecologising of genre innovation.

Fashion and media innovation

As a domain of design and a significant part of global commerce, fashion oscillates between art, industry and culture. Fashion is increasingly perceived as playing an important role in culture. It is seen as not just a parasitic entity, which draws cultural credibility from the cultural elite, but as a creative and generative force in cultural production (Taylor, 2005) that is itself mediated. The fashion industry, its art, artifice, trends and promotion, thrives because it engages with a variety and blend of genres that are embedded in its own worn and wearable artifacts. However, compared with half a century ago, fashion is now increasingly present in a diverse range of communicational settings and is a mediated entity online in emerging digital genres. Fashion appears in a range of formats such as short online web films (Muriale, 2014) and on socially networked platforms such as blogs, Instagram and Twitter (Kamais \& Munt, 2010). Nested in a digital media landscape in flux (Karaminas, 2012), the mediation of fashion is fundamentally distributed in nature. As commercially intertwined with cultural and artistic innovation and co-production in adver- tising and branding, the mediation of fashion has changed significantly with the advancement of social networking platforms and services. How these changing conditions for mediation are reflected in articulations of fashion as distributed moving image, we argue, may analytically be grasped more fully if investigated in terms of genre ecology as opposed to as isolated expressions.

As fashion is mediated across a range of media types and genres, one major development has been that fashion brands take on the role of patrons of fine art (Ryan, 2007; Skjulstad, 2014). This is evidenced in how fashion brands commission largescale architectural projects in collaborations with leading architects such as Frank Ghery, OMA and Herzog \& de Mauron, or establish art foundations and museums. In terms of media commissions and collaborations, fashion designers, fashion brands, digital artists and film makers show their works on an extended, digitally mediated and distributed catwalk and as part of this, fashion labels and other fashion industry actors take on moving images in their mediational practices (Uhlirova, 2013a; Uhlirova, 2013b; Khan, 2012; Muriale, 2014).

The term fashion film, used by and grown out of the fashion industry and circulated on line (Uhlirova, 2013b) describes an emergent genre, and as a mode of moving fashion photography that captures and negotiates the alluring, poetic and, at times, bizarre world of fashion. Fashion film is a complex genre we argue, in that it blends and borrows a variety of genre elements and features from other domains and weaves them into expressive and projective mediations that are simultaneously artistic and commercial. Fashion film encapsulates a spectrum of film genres from traditional advertising films, and music videos, to short experimental, sometimes even abstract ones. While fashion itself and its branding and popular cultural vibrancy "on the street" have become increasingly implicated in one another's value chains, visibility, and circulation effects (Kamais, 2010; Gaugele, 2014), fashion film is a meta-genre of sorts. It is at once a mixture - selection and coalescence, static form and emergent expression - of genres and elements of genres that together undergird, wrap over and layer the creative and the commercial. This layering involves a range of different media, platforms, networks, genres and contexts with opposing and at times conflicting value systems. Genre ecology makes it possible to see this as more than context, but, as we argue, it is also the layers that are are woven into the very genre and its distributed articulations. 
Fashion film and genre

The genre of fashion film interests us because it is a mediated device for distributed branding, for the digital generation of appetites and taste, and for the circulation online of views of fashion that are represented in dynamic media out in the world. As a digital genre, fashion film is linked to actual physical contemporary events, to current and historical practices in the industry. Textually, fashion film at times mediates these contexts reflexively and ironically and thereby points to its genre innovation as a culturally constituted formation and expression. Here we follow Miller's notion of genre as social action (Miller, 1984). In this view, as will be elaborated below, genres are socially and culturally located in situations of emergence, action and use. As with web-based publications more generally, fashion films are polymorphously constructed and consumed: they are composed through a mix of media, they function as distributed communication, and draw together a variety of design and communicative practices.

We extend this view of genre as social action to socio-cultural articulation with emphasis on genre emergence and innovation in published digitally mediated expressive and persuasive communication. The main question we address then is: how may fashion film inform our understanding of contemporary notions of digitally mediated genres as emerging across media, in contexts of plural media platforms and aesthetic references?

Below we propose that the notion of genre ecology, already present in approaches to genre analysis (Spinuzzi, 2003), be extended from document and functional domains to one of cultural composition and expression in the creative industries. This extension shifts focus from historical, linear and even determinist views on genre innovation as well as ones that examine it as a matter of developmental emergence. A genre ecology view, we suggest, allows us to contextualise and investigate innovation in genre as part of a nexus of factors and features that arise through co-creation between design and media, context and use, form and function and modes of cultural expression and exchange. This multimodal, trans-medial view of media innovation allows media and communication studies to look beyond earlier views on genre as comprised of typical constituents in demarcated domains, such as film, or as arising purely through textual generation in contexts of situated socio-cultural production. We examine fashion film as an emerging genre explicitly embedded in, and as incorporating a range of textual articulations in the mediationally relevant contexts of fashion film. The genre of fashion film refers to the aesthetic politics of fashion (Gaugele 2014) and it explicitly comments upon mediated assemblies of fashion and digital media which transgress genres, platforms and contexts.

\section{Directions}

In the middle section we perform close critical textual analyses of selected fashion films that we have chosen on the basis of both their prominence online and in the fashion industry but also as embodiment of cross-platform genre formations with specific and strategic circulation of cultural references and connotations. Contextually, and with reference to our own practice-based knowledge, these selections have been made on the basis of extensive viewing of fashion websites, communication design production and research especially on web and mobile media over two decades and research into digital media, digital portfolios and online branding and advertising. Our views are developed ethnographically from experience as consumers of cultural texts, as media critics and digital media makers as well as researchers investigating relations between technology, media and culture in a variety of contexts. 


\section{CONCEPTUAL FRAMES, MEDIATED PRACTICES}

Media, design and innovation

Media and innovation have been closely entwined in plays between praxis and analysis. Paintings on cave walls both symbolised the lifestyles and activities of hunter-gatherer societies while externalising material cultural representations; Vertov and Eisenstein built conceptual and analytical readings of film through practices of making and these were spooled back into filmic narratives, for example. Relations between media and innovation occur and are enacted between and across a number of planes as outlined earlier in this journal by Josef Trappel (2015). He proposes refining a media innovations research agenda via Communication Innovation Studies (CIS) and levels of value chains in the processes of developing self-awareness on the part of businesses. Levels included are a) structural conditions, b) content production, c) communication and media economics, d) distribution and delivery and e) usage/user experience (Trappel, 2015: 15). These levels inform our view on media innovation in terms of genre and genre innovation, and are brought together also in the study of actual textual articulations via the concept of ecology.
In this article we focus on the fashion film as a digital genre that has emerged since the turn of the $20^{\text {th }}$ century. Fashion film has been deconstructed within fashion studies, principally in the 'foundational' work of Marketa Uhlirova (2013a; 2013b) that does address it in terms of genre. In contrast, the object of our analysis is the complex, cross mediational innovative nature of fashion film as a distributed genre. Our focus is not on film but on how, at the level of cultural expression, this slippery genre - industry named and developed - is realised and may be understood through situating it as self-reflexive web and mobile media located cultural expression. Here we extend Uhlirova's marking of fashion film as an internet "genre" (Uhlirova, 2013b: Kindle) to an ecological view of genre in order to more fully grasp how fashion films may be designed for multiple contexts of reference and circulation, that is, for galleries and film festivals as well as for mobile and web display as part of popular culture.

Media and genre innovation occurs within the contexts of cultural media production. This may be understood from a culture industries perspective (e.g. Hartley, 2005). Such a perspective allows us to unpack genre with respect to a mesh of prac- tices, products and processes of co-creation in contexts of political and cultural economy (e.g., Lash \& Lurry 2007; Couldry 2013). Digitisation has had profound consequences for how fashion is branded and advertised, as well as for how the mediation of fashion is articulated in and as ecology, that is in a range of culturally and commercially interlinked settings and contexts. These changes including the following:

- transformation of fashion brands into media and communication entities where cross media concerns are a clear part of fashion houses emerging role as patrons of art and media

- the prevalence of media in many professional work practices and design based articulations of fashion in the creative industries, drawing on legacies but realised through media innovation

- complex interconnections between different media platforms, technologies and users compared with earlier formations and influence development, processes and articulation

- the emergence of new media and design networks whose actors co-produce new content, expressions and forms in the media and cultural sectors. 
We argue that these characteristics may be understood as emergent, interrelated, dynamic and transmedial and central to understanding genre in terms of ecology. They are part of the changing textual and contextual dynamics of production and consumption of fashion and of changing cultural articulations of genre.

Genre and (digital) cultural production

To situate our own genre ecology view on fashion film as genre it is necessary to back track slightly to summarise key approaches to genre and how genre has been framed in studies of cultural production, consumption and critique. Debates have taken place about the definition and scope of genre and genre innovation. These have in part been within disciplines such as film or linguistics. Types, properties and features of genres have resulted in conceptual and typological frameworks that have not always been in close dialogue as to their textual and intertextual referents. Genre has been discussed widely in disciplinary domains, such as literary, media and film studies (e.g., Bakhtin, 1981; Bordwell, 1989), linguistics, discourse analysis, theoretic and writing studies (Freedman \& Medway, 1994; Berkenkotter \& Huckin, 1995; Swales, 2004) and more recently game studies and cross platform digital media. Much of this has been textual analysis to locate, identify and categorise the constituent features of genres; work in applied discourse and writing studies has centred on genre as textual production in a sociocultural and developmental learning view (Prior, 2009).

Few of these studies, however, frame genre in terms of innovation that is linked to cultural production practices. Much innovation theory in media studies has been about diffusion and less about how genre is composed, constructed, communicated and conveyed in terms of modes of cultural production and increasingly co-creation and distributed communication. Miller (1984) has framed genre in a model of social action. At the core of her approach is attention to the action used to accomplish the social purpose of a genre, not merely the prior focus on substance and form (Miller, 1984:151). Genre may thus be understood in terms of social action; meaning is derived from the situation and the social context out of which the situation emerged and arose (Miller, 1984: 163). It is the rhetorical means genre provides in cultural life that is of interest: "A genre is a rhetorical means for mediating private intensions and social exigence; it motivates by connecting the private with the public, the singular with the recurrent." (1984:163). In this approach Miller (1984) argues we focus on actions used to realise genre and not the typical attention to substance and form. Taking on board Miller's focus on genre as generative, and viewing meaning as dependent on the situations and contexts in which a genre arises (see also Miller, 2015), our focus is not on genre as structure in context, but how genre may be understood in terms of ecology.

Here our work aligns with that applied to online communication and to blogs in particular (Miller \& Shepherd, 2004). In their rhetorical analysis of blogs as social action, Carolyn Miller and Dawn Shepherd provide an extensive view on the cultural conditions for blogs as articulations of communicative action and the various subject positions blogs support and make possible. In particular, they stress how blogs must be understood as fundamentally culturally situated for social action to take place. According to Miller and Shepherd (2004: 2), for genres to evolve, they have to “... allow for the incorporation of novelty, the accommodation of changed constraints, the tweaking of ideology which eventually leads to the redefinition of decorum, and the imposition of a new ideology". These 
views on genre, novelty, and ideology, when paired with a notion of ecology, allow us to position fashion film in the centre of a wider discussion of media innovation at the level of genre ecology as well as ideologically related to art, commerce and cultural production and consumer culture.

In terms of innovation, more ad hoc, emergent and process-oriented approaches to genre have been developed on the basis of empirical studies (e.g., Van De Ven et al., 1999) that allow for divergent and convergent patterns of more fractally framed development of genre. Properties and characteristics of digitalisation, such as repurposing and mixing of style, content and form, have contributed to increased application and recognition of known genre formats and related the expectations on the part of audiences and ultimately user-consumers. Media domains have seen considerable transformation due to the uptake of digital tools and modes of distribution. One case in point is that of the news industry where processes of news-gathering and genres of news mediation have undergone considerable change. As Freadman (2015) reminds us, though, genres provide openings for articulation and it is this level of realisation that we see operating through the notion of genre ecology.
In earlier work we have concentrated on the articulation, or textual strategies in a wider communicative ecology of digital advertising. We looked at a web-based auto industry campaign concerning the promotion of a luxury hybrid SUV (Morrison \& Skjulstad, 2010) and at the promotional strategies of a then leading mobile phone producer through a viral and participatory form of media advertising that invites users to upload their own adverts and evidence of their literacies (Morrison \& Skjulstad, 2011). Arvidsson (2006) argues that brands have become an important factor in people's lives. In his view, through tapping into specific value systems, brands have the ability to inscribe these into everyday consumer practices, thereby linking decisions in life and life style to consumerism and transforming everyday life into economic value.

The importance of genre as social action (Miller, 1984; Miller \& Shepherd, 2004) is that it allows expressions of genre at the level of mediated articulation to be understood as socially and culturally situated and as growing out of and evolving through practice. This enables us to see genres as sites where media innovation fosters continual change, and as instances of social action in terms of ideology. In catering to a range of different audiences across digital formats and platforms and across cultural domains, fashion is mediated polyvocally and in ways that connect everyday social media practices with sophisticated fashion mediation, inscribing as discussed by Adam Arvidsson (2006), fashion and culture coupled with consumer culture into every day life. Fashion film seen in terms of genre ecology moves the negotiation of overlaps and ideological distinctions between art and advertising into a digitally networked and distributed cultural environment, rendering traditional distinctions between roles, genres and rhetorical positions into a state of flux.

Commissioning films from artist film makers, entering film festival screenings and designing for careful referencing of works, and discrete display of affiliations to artists and specialist professionals relevant to the fashion brand, is part of an ongoing negotiation between art and fashion. The relation of fashion to art and commerce tends to be viewed from polarised positions, and as stated by Mitchel Okley Smith and Alison Kubler (2013:14), "Fashion is popularly understood to be fickle, transient and largely driven by popular culture, whereas fine art is viewed as timeless, considered and elitist”. These binary positions are present in fashion film. To 
more fully understand the genre, a notion of ecology - encompassing cultural references and legacies of established genres of both elitist and popular culture - presents a wider frame through which we might view fashion film.

\section{Towards genre ecology}

Genre may be understood as part of what David Gauntlett (2015) refers to as a creative turn in media research. This turn encompasses a dynamic of textual and contextual production. It extends beyond earlier conceptualisations of media convergence (e.g., Jenkins, 2006; Deuze, 2007) to what we see as a developmental and exploratory textual expression of genre innovation that is part of a wider communicative and indeed genre ecology. Jay Lemke (1998: 286) suggests that:

Instead of theorising causal relations from one autonomous domain to another ... if we unite all these domains as participants in the myriad subnetworks of an ecosocial system, we can give detailed accounts of their interdependencies and the self-organising dynamics of this complex system.

This is in tune with Miller's stance on genre as social action in the interconnectedness of an ecosocial system that encompasses given norms that are structured and stable and part of socially shaped schemas for engagement, while also being in emergence as discourses in the making (Morrison 2010; see also Miller, this issue).

The notion of ecology here needs some disambiguation as it is used in environmental and natural sciences and anthropology as a mode of cultural ecology (e.g., Kottak, 1999) and media studies. Cultural ecology sees the natural and physical environment as having a non-determinist influence on our cultural and socio-material ones. We adapt to the systems and forces of the "biosphere" yet we also develop cultural references and relations to it through expression and articulation of cultural activity and production, such as in the work of Gregory Bateson (1973) and systems theory more generally. Important to note is that this approach has been critiqued for an element of environmental determinism. Drawing in part on this tradition and its connections within social and cultural anthropology, and once firmly a part of structuralist views on media in the 1970s in the work of Walter Ong, Neil Postman and Marshall McLuhan, the notion of media ecology has now shifted to include atten- tion to context and interdisciplinarity (Strate 2010) and appears in domains as platform studies (e.g., Fuller, 2005).

The term genre ecology has also appeared within the literature on genre, though not in that on media ecology and media innovation. Genre ecology has tended to be developed and applied with reference to technical communication and the role of genre in organisations (e.g., Spinizzi, 2003). Clay Spinuzzi and Mark Zachry (2000: 202) propose that genre ecology is a framework suited to the study of "compound mediation". Drawing on activity theory, by this they mean the mesh of artifacts, from software code to post it notes, that are involved in people making mediated meaning in collaborative, coordinated and process based work activities. They highlight three aspects of genre ecologies. They are 1) governed by contingency and come into being through processes of negotiation and change, 2) typically decentralised in being distributed in their combinatorial composition between design, intention and usability, and 3) relatively stable in ways users make connections between the genres they use, despite contingency.

Spinuzzi (2002) conceptualised genre ecology as an heuristic, analytical framework to account 
for the matrix of artifacts, communication types and practices that are employed in technical communication to mediate the activities of work. This is work that is characterised by stability but also contingency and interpretation, more conceptually than functionally. "Unlike other frameworks dealing with compound mediation ..., the genre ecology framework is centrally concerned with how people interpret genres, how they contingently intermediate genres, and how these contingencies become relatively stable over time ...”. (Spinuzzi, 2002: 200). He sees genre as tools in use and not artifacts in isolation (Spinuzzi, 2002: 201) and that interecology elements may also be examined further, such as in the uses of genres in technical communication and collaborative work in teams.

Thomas Eriksson (2000) included genre ecology in research into "babble" in computer mediated communication (CMC). This Eriksson interpreted in conversational terms as "global pull", "topical pull" and "conversational impetus" as means to unpacking how participants are recruited into different genres. We offer three core more culturally located discursive categories (Commissioning, Disarming and Popularising) through which fashion film may be seen as a mediated genre innovation.
As we show below, genre may be seen as part of a complex and intertangled weave of mediated fabric, as articulation from within the culture industries that references its own 'patterns' and public performative enactments. These enactments are embodied, screened and situated through design and as design. In order to clarify this we now move to unpack relations between digital media, brands and fashion.

\section{Fashion film: legacies and projections}

The history of fashion as moving image is rich and it encompasses a range of genres and contexts as fashion has historically been a vital ingredient in cinema (Uhlirova, 2013a; Uhlirova, 2013b; Gaines, 2000) and intrinsic to the Hollywood star-system and contemporary celebrity and media culture (Church Gibson, 2012). Within film and fashion studies, fashion in film has been scrutinised extensively (Warner, 2012). However, outside of traditional cinematic genres such as Hollywood costume dramas and documentary genres, explorations of fashion and the moving image in digital and networked domains have been given less attention outside of fashion studies, as has fashion mediation as site for media and genre innovation.
However, fashion designers and mediators have a rich record of early adoption and adaptation of digital media technologies. For example, Helmut Lang's Fall/Winter 1998/1999 collection was the first to be only live-streamed for an online audience, causing scandal among those deprived of their usual front-row seats (Muriale 2014). In terms of moving images on the web, discussing the evolution of fashion film without stressing the importance of the web based platform Showstudio. com, established in 2000, and which has been pivotal in developing the forms and formats of fashion film in close collaboration with a range of designers, artists and photographers is difficult (Muriale, 2014; Uhlirova, 2013a).

Fashion and media are entwined in a variety of ways, and the range of linkages between fashion, art and media are so diverse and are beyond the reach of this article. Uhlirova (2013a; 2013b) traces her historical account of the development of fashion film back to early cinema of attractions (Gunning, 1990) and to the tinted films of the Pathe brothers and to films by George Méliès at the beginning of the $19^{\text {th }}$ century. She discusses fashion as proposed by Gunning, as exhibitionistic cinematic practices celebrating the possibility of being able to 
show something via the moving image (Uhlirova, 2013b; Gunning, 1990).

There now exist a range of Fashion film festivals, devoted only to the screening of the whole spectrum of moving fashion imagery. These festivals include the Berlin Fashion Film Festival (BFFF) ${ }^{1}$ and A Shaded View on Fashion Film (ASVOFF), ${ }^{2}$ which since its launch in 2008, as stated on its website, "has gained critical acclaim for encouraging both emerging and established artists to reconsider the way that fashion is presented and for challenging the conventional parameters of film." According to Nathalie Khan (2012), the mediation of fashion as moving image has not only been pivotal in changing how fashion is perceived and understood, it has also changed how fashion is produced and embedded in and as culture.

However, the emerging genre of fashion film has received less scholarly attention and has largely been overlooked by film scholars, with a few notable exceptions such as Uhlirova (2013a, 2013b).

1 See http://www.berlinfashionfilmfestival.net/about (Accessed 14.10.2015).

2 See http://ashadedviewonfashionfilm.com (Accessed 14.10.2015).
However in fashion studies, Khan (2012a; 2012b) and Sabina Muriale (2014) have inquired into fashion film and looked to the study of digital media, for example as found in the writings of Lev Manovich (2001). These authors have focused on ways in which fashion film as an emerging genre is embedded in digital media culture and has paved the way for further linkages between media and fashion studies. This is a cultural setting which is crucial in changing how fashion is conceptualised, produced and mediated.

Extending this view, Khan (2012) has inquired into the non-narrative qualities of the films of Hogben for the fashion designer Gareth Pugh. Kahn links these non-narrative qualities, such as its disconnection to the real through disruption and repetition of movement, to simulation of the reality of the garment itself, to Benjamin's writings on the object of art in the era of mechanical reproduction. According to Khan (2012: 259), "The moving sequence is not just the index of the real but also ontological image convention, itself far more concerned with the nature of the image than with its content". She links the film to Manovich's concept of permanent presence (2001), as the restrictions of time and space are of little relevance in digital media. As stated by Khan (2012: 248), "The digital image has no natural end, but instead offers permanent presence. It is this link between the moving image, consciousness, and the "here and now" that suits our notion of fashion”.

These views on fashion film point to it as being very much a matter of hybrid media construction and communication. A variety of multi-skilled artists are now drawn into fashion film in the ways that offer mediations of fashion to new audiences outside of the white cube or film clubs. Importantly, as a genre fashion film works are often commissioned. Internationally profiled film directors, such as Roman Polanski, Agnes Varda and David Lynch, have been commissioned to direct short films for fashion brands such as Prada, Dior and Miu Miu. Seen together, these works articulate the transference of aesthetic value and financial means between film and fashion, as well as the tensions between artistic autonomy and more traditional restraints of advertising.

Fashion film is one of the means through which fashion is circulated within a wider and indeed global fashion culture and commercial economy. However, it needs to be understood as more than simply mediation and exchange. Helen Warner (2012: 122) considers the development and prevalence of new media as important forces in a trans- 
formation of the ways in which fashion is produced and consumed, but also how such a development has "... forced traditional platforms of print and screen media to adopt innovative strategies in order to reach consumers".

How these films are mediated alongside with a video of the latest fashion catwalk show and digital reproductions of the print advertisements of the season will be discussed later in the article with respect to the notion of genre and media ecologies. However, we need to heed the observations of one of the leading theorists on fashion film, Uhlirova, who argues that the genre of fashion film is a messy one, one of diversity, and must be understood "As a heterogeneous cultural form with no clearly predefined stylistic criteria or conventions, the fashion film eludes any attempt at a neat classification as a genre" (Uhlirova, 2013b: 120).

\section{INSIDE GENRE ECOLOGIES IN FASHION FILM}

Three connected concepts

In the selected films below, we show how fashion films are embedded in a distributed media cultural landscape. Here, the films add extra layers of meaning to a fashion brand, but may also be viewed as articulations of how a genre may evolve through media innovation that takes place across discursive domains and as instances of transversal genre innovation across and beyond conventions, formats and platforms. We address this via three chosen and interlinked concepts arrived at from bottom up reviewing of fashion films, earlier research in branding, multimodality and genre analysis. These are: a) Commissioning , b) Disarming, and c) Popularising.

By commissioning we mean how cultural production is enabled through the financial support from a brand who acts as a patron of art, and as we argue, as patron of media design, and at times also of media and genre innovation. In the context of fashion film this refers to the generation of crossplatform content that is entwined within a media ecology, textually and contextually through a number of discursive meditational moves.

Disarming refers to how multiple and conflicting mediations of a brand's image are layered on top of each other so as to convey facets to a brand's identity. Humour, self reflexivity and irony is added to sleek and conventional mediations of a fashion brand. Concerning fashion film, we examine how the genre is realised mediationally through humour and irony as part of a wider ecology.
Popularising centres on tapping into formats already established and migrated from tv to the internet and to mobile platforms, and to how fashion enters digital popular culture fully through artist collaborations with musicians, extending and transforming genres such as the music video so as to also explicitly include the mediation of fashion for specific brands. Our focus in presenting fashion film as genre is to show how the catwalk is extended and transformed via popular celebrity culture.

These concepts offer a transmedial and multimodal view on how the genre of fashion film might be understood as positioned in the cross-sections of the mediations of outcomes of interdisciplinary aesthetic practice, the context of creative media ecologies and the aspects of innovation central to both media development and the evolution of fashion. The selected films show how fashion film as a genre sits between these interconnected areas of study. The focus on cross-platform commissioning allows us to see how fashion film as a genre may be understood as situated in the creative culture ecologies as cultural, meditational acts of communicative construction. However, it may also direct attention to how such media commissioning practices render critical positions to contemporary branding difficult. 

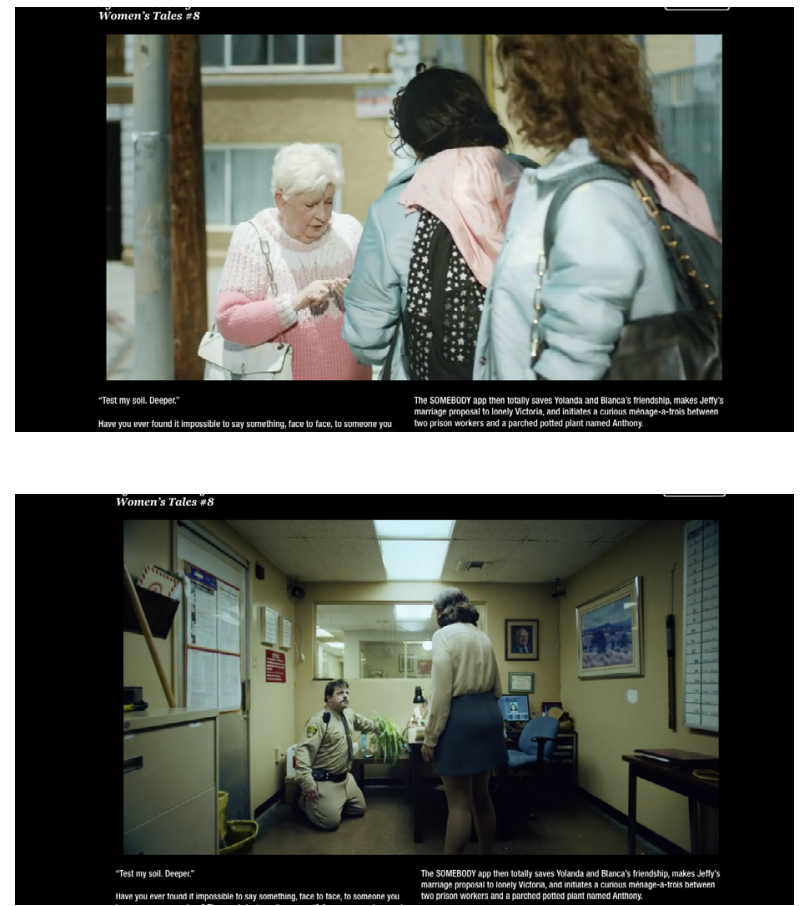

Figures 1 and 2. Screen grabs from Somebody, directed by Miranda July and mediated at Miu Miu's website as part of the commissioned series of films, Women's Tales.
Commissioning: the generation of cross-platform content

Miu Miu, a brand owned by the Prada Group, commissioned a series of films directed by a group of leading female filmmakers. According to Miu Miu's website, the films explore aspects of contemporary women-hood. At the time of writing, ten short films are presented chronologically on the Miu Miu website. Among the filmmakers we find the director Agnes Varda, known for her historical role in new wave cinema and in experimental documentary.

One of the films, No 8, Somebody (2014), directed by Miranda July, presents a series of interlinked, personal, yet mediated, encounters enabled by the fully functional mobile application Somebody (2014), freely downloadable from Appstore (Figures 1 \& 2). The "app" provides the possibility of engaging other users, enabling them to take part in face-to-face encounters with strangers when delivering a message as a proxy for the sender. The series of scenes in the film all includes the app in what includes a relationship break-up, a reconciliation between friends, a marriage proposal, as well as an exchange between a demanding texting plant and two prison officials. The film is structured as a series of encounters made possible by the app, giv-

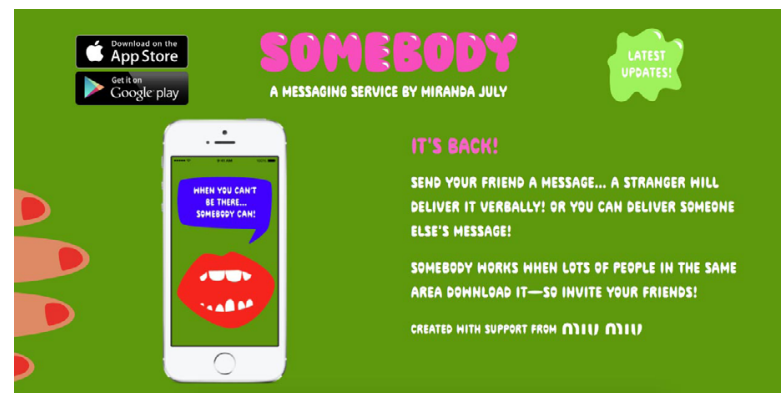

Figure 3. Screen grab of the app Somebody, featuring in the film Somebody by Miranda July, commissioned by Miu Miu.

ing special attention to the personal and authentic as mediated through a digital application.

The app was launched at the Venice Film Festival along with the film (Figure 3). ${ }^{3}$ The fact that July's creative practices are fundamentally interdisciplinary, as she is an actor, filmmaker, artist, and journalist - and that an app developed alongside a fashion film is "screened" as part of a film for a fashion label tells us how fashion film as a genre is deeply interconnected also on an institutional level with the film industry, the fashion industry as well as with industries within digital design for phones.

3 See http://www.mirandajuly.com (Accessed 18.10.2015) 
In the website of Miranda July, the app development is described under the category 'art', and in the text describing the app, hotspots with a critical mass of users of the app listed are primarily art museums. Also, given July's previous treatment of the topic of fashion, a range of other art projects, such as The Miranda, an art project shaped as a shoulder bag, are presented in the context of an art fashion store online. ${ }^{4}$ In acting as a patron of the arts, Miu Miu sets a whole web of references to artistic practices relating to the interconnectedness of art, fashion and media in motion in collaborating with July, thus extending the Prada group's role of patron of fine art as discussed by Ryan (2007) into the wider context of media and popular culture at the same time as including cinema.

In a video interview about the process of developing the film included in Miu Miu's website, July points to how the Somebody app was developed in parallel to the making of the film. She expresses surprise that Miu Miu covered the costs of developing the app. In this video interview she also discusses the role of costume in her filmmaking. According to July, the collection aided her as a filmmaker in

4 See http://welcomecompanions.com/collections/classics/products/ the-miranda-limited-edition (Accessed 18.10.2015). providing her with cues for her development of the characters in the film. Her selection of characters, environments and situations in which the actors wore pieces from the Miu Miu collection linked to every day settings, is breaking with the notion of high fashion as something out of place in the mundane everyday world. The garments and accessories featured in the film are shown in contexts other than what might be expected in a fashion film.

Many of the garments are presented in most unglamorous everyday contexts. For example, an elderly woman interrupts two young women who are quarrelling. They turn their Miu Miu-clad backs to each other. The elderly woman walks off and we are drawn to the fact that she is wearing a knitted jumper and carrying a bag from the same collection. Most of the costumes in effect are displays of the collection. Instead of aestheticizing the collection further as might be anticipated, the garments blend into a very "real" everydayness conveyed in the film. This realism is also partly achieved in that the app Somebody is fully functional and has been designed in tandem with the film production for use in the real world. This knowing repositioning of a collection that presents luxury appeal serves to add a more human side to the brand allowing it to be presented simultaneously as both glamorous and unglamorous in use. The glamorous version of the collection conveyed through moving images is available to the viewers of the website in a filmic presentation of the season's catwalk show.

Central to the Prada group's branding practices is the international Rotterdam-based partnership OMA - centring on urbanism, architecture and culture along with its related company AMO, a design and research studio working in a range of domains such as fashion, publishing, and cultural analysis. The aim of Rem Koolhaas (the architect, theorist and film-maker and the most publicly known among the partners) has been to re-conceptualise shopping into a cultural activity (Chung et al., 2001; Koolhaas et al., 2001). This has been pivotal in steering commerce into being recognised and appreciated as a cultural endeavour. AMO's longstanding collaboration with the Prada is but one example of high fashion brands that engage in what often is being referred to as "high culture". Such collaborations are themselves part of communicating the brand's identity, and extend also to include large architectural projects (Klingmann, 2007; Ryan, 2007; Skjulstad, 2014).

How and why fashion houses such as Prada now act as patrons of the arts and architecture is analysed in depth by Nicky Ryan (2007). She inter- 
prets Prada as a modern and enlightened patron of "avant-garde" art and architecture, focusing in particular on the ongoing collaboration between Prada and OMA/AMO. In focusing on the production of symbolic capital, Ryan (2007: 7) observes that “... what is at stake is the corporate appropriation of 'avant-garde' positions within the parameters of the market." Drawing on Ryan's views, such symbolic capital is also generated in a range of closely related fields that all share the allure of what were once bastions of refined "high" culture, such as art, architecture and museums. The role of a liberal patron makes it difficult to adopt a critical position on the brand.

However, fashion's relations with and dissemination through media may also be seen in tandem with the industry's manifold relations with the art world. The expansive role of Prada as patron of the arts is also seen in the Prada Groups' branding of its other label Miu Miu. The Fondazione Prada focuses on fine art (Ryan, 2007); Prada and Miu Miu commission films, such as the short film $A$ Theraphy (2012), directed by Roman Polanski and starring Helena Bonham Carter and Ben Kingsley. In commissioning a series of films for these internationally established brands, as well as the app for Miu Miu, the brand builds corporate reach into cin- ematic and digital development.

This is not just a very recent development in terms of film commissions. As early as 2005, Prada collaborated with Ridley Scott and his daughter Jordan Scott in directing the short film Thunder Perfect Mind that was released to coincide with the launch of Prada's fragrance, and screened for the first time at the Berlin International Film Festival..$^{5}$ Instead of art patronage, media patronage is brought to the fore in the form of curated media and filmic content. In extending Ryan's critique of Prada as a patron of arts (Ryan, 2007), we include how commissions and curatorial practices relating to fashion film and digital innovation in the context of art consolidates the brand's position as enlightened and liberal cultural institution. A brand that is positioning and presenting itself as a connoisseur and as an enabler of cultural production, however, may effectively disarm critical voices, as Ryan suggests, especially when the commissioned works enter the film festival and art museum circuit.

Disarming: fashion mediated via humour and irony Fashion is unquestionably known for the recycling

5 See http://www.prada.com/en/a-future-archive/short-movies/movies/thunder-perfect-mind.html (Accessed 14.10.2015). of earlier styles and the generation of new ones and recombinations of the two, and as fundamentally communicative (Barnard 2001). Fashion is being constructed and explored online with humour in self-reflective twists on the stereotypes and clichés available to already media savvy audiences bored with the aestheticized imagery that saturate beauty and fashion advertisements. However, in parodying such clichés - as seen in Matthew Frost short film for spoof label Viva Vena, a fictive offspring of the brand Viva Cava Fashion Film (2013), stereotyped conceptions of the genre appear (Figures 4 \& 5). This reflects a genre that is crowded with beautiful, but poorly narrated films, characterised by quasi poetic-slowness and lack of narrative motivation. As a genre in formation, one with few established conventions, the filmmakers are situated in a range of different contexts, such as for example fashion photography or styling. Developed in creative contexts where the quality of fashion styling, hair, make up, and mis-en scene - more than perhaps narration - is central to mediating fashion, the films still tend to be critiqued from inside the industry. However, while also rejecting strict rules and conventions, the genre of fashion film remains open for explorations of moving fashion imagery by amateurs and creative professionals alike. 
Self-absorption and self-promotion is the theme of this ironic film. A young woman played by Lizzie Caplan whispers sensually about her interesting, trendy preoccupations: she likes records from the sixties, she edits a blog, she is interested in art (performance and collage), and so on. She even thinks in French. This film is shot in a soft light and with ambient music that helps create a dreamy self oriented perspective as Caplan rambles on. Suddenly her friends appear, and as they pull her out of her inner world she says, "I'm in an art fashion film", to which they reply, "No, it's a commercial". These onlookers and we the online viewers are joined in placing this first-person filmic representation in its place within a wider industry and as a piece of selfmirroring that is seemingly unaware of its commercial genre identity. Uhlirova (2013b) says that fashion film is often queried as to whether it is art or advertising; this binarism is not productive analytically in understanding the genre. The film does not merely reference other fashion films. Rather, it is articulated as a playful and critical meta-comment on how the genre juggles with the recurring debate about such films as being advertising or art. Rather, fashion film oscillates between these spheres. The tensions and ambiguities in the relations between these at times opposing positions may be under-
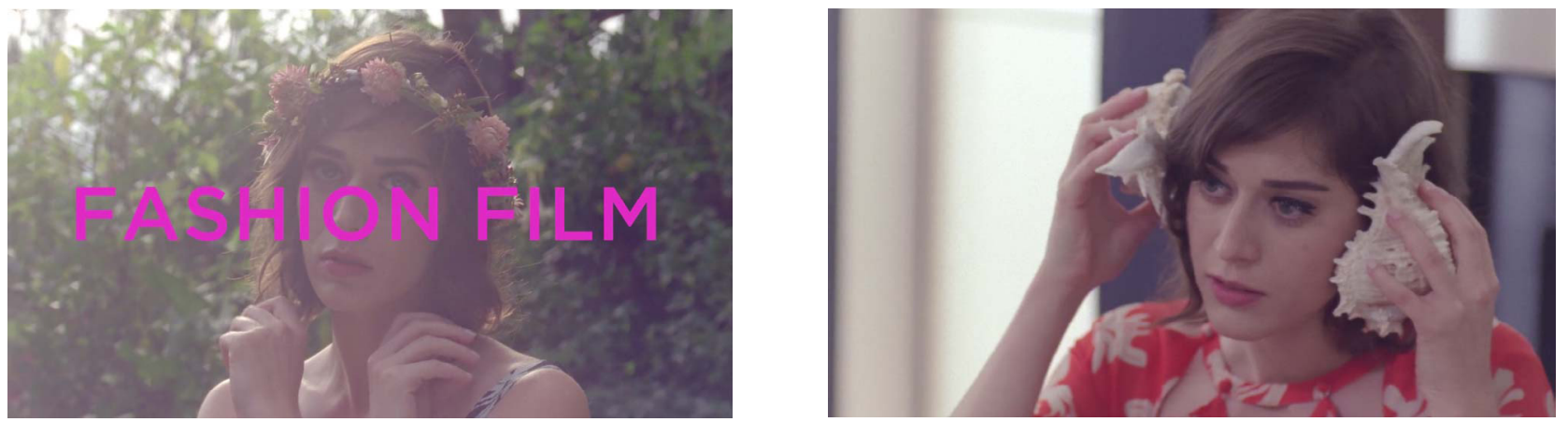

Figures 4 and 5. The genre of fashion film is also hilariously parodied as a meta-comment on the genre, as seen in this film labelled Fashion Film, directed by Matthew Frost for Vena Cava under the spoof name Viva Vena 2013.
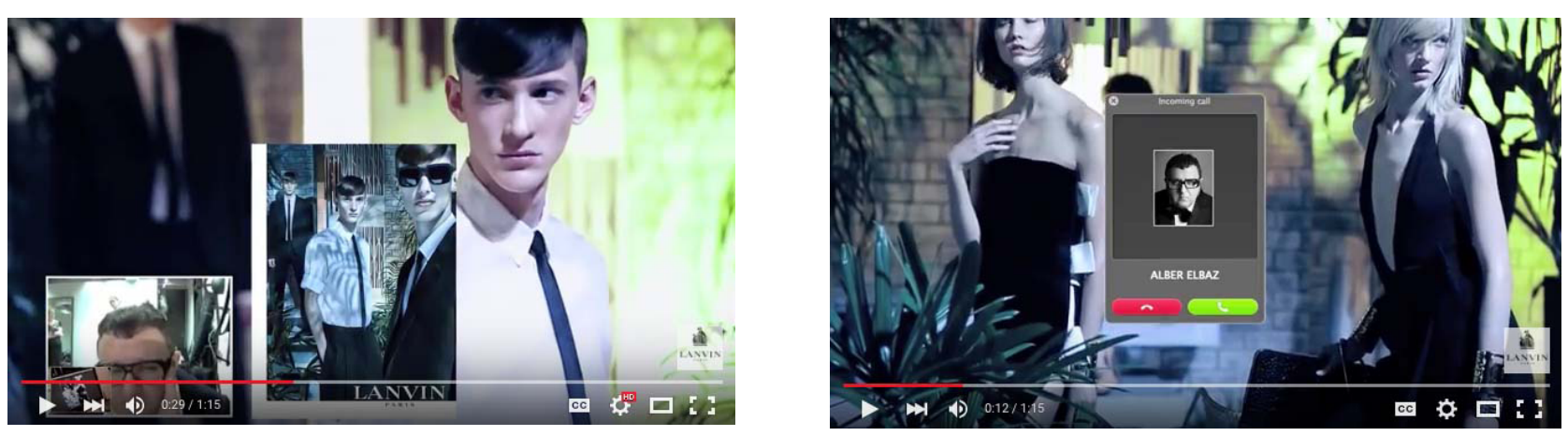

Figures 6 and 7. Screen grabs from the short online advertising film Spring/Summer 2013 for the fashion house Lanvin, featuring its creative director Alber Elbaz, who appears as a comic figure and as parodying conceptions of the 'star' fashion designer. 
stood as inherent in the genre, and as central in our ecology framing of fashion film. The relationship between fashion and art has been productively scrutinised by among others Vicki Karaminas and Adam Geczy (2012), who acknowledge the close collaborations between artists and fashion designers across a wide range of contexts of cultural production. To view fashion film as either art or advertising may lead us to overlook important aspects of contemporary fashion mediation and promotional and persuasive communication as opposed to seeing such relations as vital to the genre and its wider ecology.

Humour and self-reflectivity is central to many fashion films, as for example seen in short film by Lanvin for the spring/summer collection 2013. The digitally mediated character of the film itself is central to the narration, presented as a Skype conversation between Lanvin's creative director at the time, Alber Elbaz and the organisers of the fashion shoot for the season's ad campaign. The imagery and the dialogue in the film are completely out of sync, making it obvious that the creative director (who plays himself) is ironically not really paying any attention to what he sees at the shoot with Steven Meisel, and parodies the stereotyped image of the creative director of a major fashion house. The video is featured on YouTube, and has been spread and commented upon. Online fashion-newspaper thebusinessoffashion.com, commented on the film, as Internet Culture interfering with the airtight perfection of print fashion media.

The film adds a meta-layer of meaning not present in the print advertising campaign, and while the print advert may be read separately as a conventional high fashion advertisement, the film conveys Lanvin as playful. The film may stand alone, as can the print advert. However, if the film and the print advert are regarded as a composited construct, a more nuanced image of the brand appears. The film might be read as modifying and providing facets to the articulations of the brand's identity while not stepping beyond the more conservative expectations of beauty and form present in the established print fashion media genres outside of the avant-garde print publications.

However, the self-reflexivity conveyed through the film is absent in the print advertising campaign. The film addresses an Internet-culturefashion savvy audience. It also addresses an audience that reads fashion across media types and platforms. The film ironically annexes a high culture view of fashion that is democratised by web 2.o technologies, blogs and social media platforms
(Khamis \& Munt, 2010). Such an audience is familiar with fashion and media and has sophisticated fashion media preferences. These are readers who take pleasure in a more challenging aesthetic mediation of fashion, and who read fashion as distributed across screens and texts.

As seen in the case of Lanvin, a film might also draw attention to and add an extra layer of meaning not available to the often more conservative campaign photographs in print magazines. This may then also add to the experience of a more nuanced and multi-facetted view of fashion media. In placing the Skype interface on top of the film, as spectators we view the film as meta-comment on the photographic setting, the art direction and styling. We look "through" the façade of the brand as displayed in polished fashion imagery to focus instead on how the brand is presented as a more humorous one than typically mediated through static images. The film provides a tongue-in-cheek meta-comment to the public appearance of the brand in print. Through this mediated and disarming marketing ploy layers of meaning are added to an interrelation of genres. As a result, two parallel yet separately designed genre mediations are interloped, demonstrating how fashion film as a genre might be more fully conceptualised as mediated 
across singular textual expressions and established genres. This, however is only possible to understand if these mediations of Lanvin are coupled and seen together as a composite entity.

Popularising: the catwalk extended via popular celebrity culture

In her discussion of the "permanent presence" of digital fashion mediation via digital moving images, Khan (2012b), stresses the importance of the Internet's capacity to mediate moving images of fashion and how fashion now needs to be understood within a digital frame. However, emerging genres of digital moving images also need to be understood as providing new conditions for fashion designers. As a result, they may be actively considered in the design process itself and at times as remediating existing genres of live fashion mediation such as the catwalk-show. Referring to a range of online sites of fashion mediation, such as Showstudio.com and Nowness.com, as curatorial spaces for staging of fashion, Khan (2012: 252) sees these spaces as challenging "... the immediate experience of fashion as live event, as well as fashion as material objects".
In Khan's discussion (2012b: 253) of the digital fashion film screened at Pitti Imagine, \# 79 (2011), the focus is placed on Ruth Hogben's pioneering work with Showstudio.com and that of Gareth Pugh and the filmic presentation of his collection that was projected onto a Florentine church ceiling. According to Khan, "Hogben's films no longer differentiate between object and representation, nor between image and physical presence, real time and projection. Non-narrative fashion film relies on simulation, as the garment is no longer present in time or space." (op. cit.).

However, when the catwalk show is replaced by the digital film, as in the case of Pitti Immagine \#79, and the film itself projects the designer's vision of the collection, Kahn links such a mediation to creative control of how the collection is to be presented. This is apparent in a more recent film the designer Tom Ford released in 2015 as a replacement for a live catwalk show for his S/S 2016 collection. Directed by Nick Knight, the film presents a mannequin disco nightclub party on an under-lit catwalk featuring Lady Gaga. The event is set to the tones of her remixed version of the 1979 hit I Want Your Love by Chic. Tom Ford, who usually presents his collections at fashion week in London and New

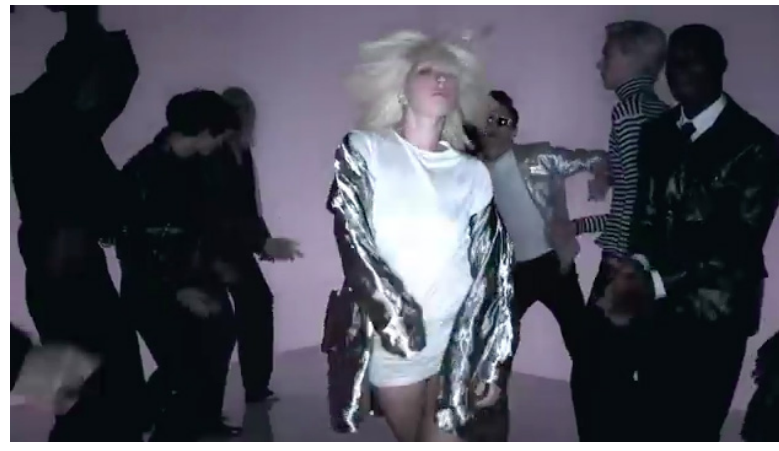

Figure 8. Screen grab for the online fashion film showcasing the Tom Ford S/S 2016 Collection by Tom Ford, featuring Lady Gaga.

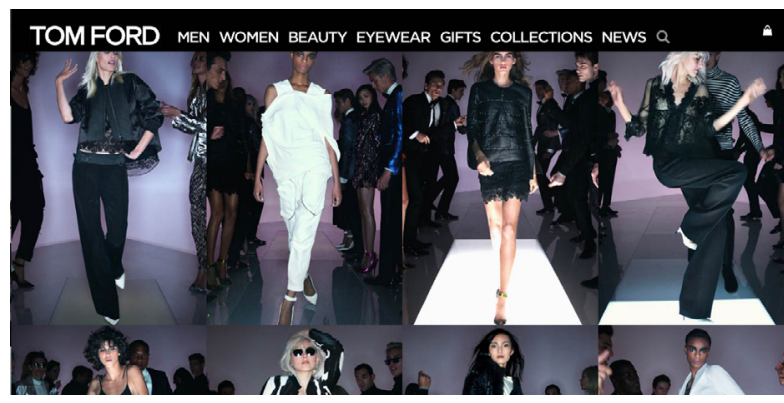

Figure 9. Screen grab from Tom Ford's website, showing the collection as a digital look book. The entire collection was photographed at the film set. 
York, released the film after an unannounced absence from the previous catwalk season.

The video catwalk show has a double funtion: while still presenting a fashion collection, it simultaneously can be seen as a music video, and embodies a complete integration of the genres of fashion film and music video. In terms of circulation, mixed techniques are used to gain attention and the astute editorial presentation as the film is designed to reach audiences far beyond the closed circles of live catwalk shows.

Writing on fashion and celebrity culture, Pamela Church Gibson (2012: 1) points to the need to see the changing landscape of fashion in close relation to emerging changes in the entire topography of visual culture, one characterised by a "... new proliferation of celebrity culture as a global, collective and disturbing obsession". However, Ford's connections to cinema are already attached to the brand, as he secured the rights to Christopher Isherwood's 1960 novel $A$ Single Man, which he modified and directed as a feature film. In this prize-winning and Oscar-nominated film, Ford added elements of fashion and style not present in the original novel. He clad the protagonist in Ford menswear, situated the characters in sleek interi- ors and conveyed his visual sensibility in the overall mis-en-scene of the film (Church Gibson, 2012). It came as perhaps no surprise that Ford applied fashion film as a vehicle in launching his S/S 2016 collection given his recent cinematic work.

The pop icon Lady Gaga features in Ford's S/S 2016 fashion film. Her connections to the fashion industry and her direct reference to fashion and art are manifold. She has collaborated with a range of designers, such as Alexander McQueen. Lady Gaga has been involved in a series of projects with Nick Knight and others via showstudio.com. Writing about the importance of the close working and artistic relations between the fashion industry and celebrities, Endora Comer-Arldt (2014: 45) points to how such relations provide an entrance to scrutinize the "... hybridity of fashion as an economic business and cultural movement". Returning to Miller (1984), genres change, evolve and decay. As with fashion film as a genre, an ecology view opens for seeing genres such as the televised music video as having evolved into a hybrid form, articulated as fashionable mediation of music, and as a celebrity-clad fashion spectacle mediated alongside the sound of contemporary popular culture. In an ecology view on genre, these films, we propose, need to be seen as interwoven into the textual fabrics spun around and across them, and as part of an extended understanding of genre itself.

\section{CONCLUSION}

We have elaborated how genre innovation in fashion film can be understood as taking place in and across the aesthetic, creative and commercial intersections of a range of domains. We introduced the notions of Commissioning, Disarming and Popularising as a means to framing and unpacking relations in a media ecology view on fashion film. These relations and their intersections can be studied and understood at a macro level as genre ecology through an interdisciplinary coupling of insights from writing and rhetoric, via innovation studies, from the cultural industries as well as knowledge stemming from studies of digital media innovation and communication design and fashion studies.

However, also at a micro level, and using the three core constituent categories, the selected films show how these overarching couplings of industry and artistic and popular cultural practices may be articulated in actual textual expressions. These are 
mediated articulations of a genre that carries configurations of the aesthetic, technical and cultural in and across media platforms and contexts. The examples demonstrate the mediational conditions that make possible the genre innovations and linkages across domains. Further, fashion film as genre innovation in its own right functions as part of the contemporary mediation of fashion. The examples also demonstrate that the notion of ecology that is central to the distributed and cross-textual conception of genre we propose may be linked to Miller's view on social action to better help us grasp genre innovation.

This we see as a form of "cultural branding" in which digital tools, technologies, practices of user generated content and evaluation, circulate online and back into and out of the world of the woven and worn. In this view, context is highly, and often ironically, located within fashion film as a genre. Such persuasion is geared towards both reflecting and constituting a form for cultural "appointment" (not just brands to royalty). In this appointment a market and cultural value positioning - fashion houses and brands become curators of fashion as a creative industry, using mergers and featherings of the artistry of fashion and fashion as art. The ensuing content circulation is centred on the curating of a social semiotics of connections to art events, galleries and contexts. At the same time, and this is a crucial cultural co-efficient of sorts, fashion film encapsulates trends and features of popular digital media culture.

Assemblies of ecological relations

Today this is a culture that is distributed. It works across platforms and it is realised via mobile relations of movement in place and time. The digital culture in which the innovation in the genre of fashion film occurs is riddled with paradoxes: of relations between seller and self, and between consumption and production. These paradoxes are evidenced in a socio-material view of mediated digital culture that is threaded through with irony and pastiche. Together these are assembled in ecological relations in and as genre. Genre ecology is a term that allows us to name, chart and transverse this complex weave of culture, design, technology, and media. Thus, the genre of fashion film needs to be understood as not only grown out of the Internet, but also as grown into its distributed textual context to such an extent that the genre cannot be understood only in terms of the films themselves.

It is the mesh of text and context, production and consumption, mediation and annotation that makes the analysis of fashion film difficult as a genre inside a media innovations frame. We hope that our article has provided some externalisation of our online viewership, reference to our own earlier work in a social semiotics of digitally mediated advertising and branding and persuasion.

We see inquiry into media innovation as largely lacking research that addresses the cultural, the expressive and the performative. We suggest that understanding of these aspects may be gleaned from the creative industries, communication design and cultural articulations in which multimodal discourses are contextually, economically and politically prevalent and grounded. They are realised as a genre of fashion film online, far from the teetering heels of the catwalk, yet, nonetheless, still stridently sure that culture matters, not only with eyes necessarily also cast to visible texture, economic fabric and underlying foundations.

Media ecologies, genre innovation and the creative industries

We suggest that fashion film as an emergent genre may be fruitfully seen as part of a wider notion of media ecologies that are apparent in the creative industries. We argue that fashion film specifically may be situated in terms of what we label a genre 
ecology perspective that is media and culturally framed not merely in terms of collaborative work activity, but also articulated textually. This perspective refers to how genre innovation may be conceived as distributed social action across platforms and meditational contexts, and potential specialist culture industry domains and media types.

As discussed by Miller (1984), genres can be conceived as organic constructs, and the rhetoric workings of genres as socially situated and as enablers of social action. Such action may be extended into a myriad of domains and audiences, as Miller and Shepherd (2004) demonstrate on blogging. However, a genre ecology view may be understood as interlinked through a distributed combination of specialist cultures ranging from artists, creative professionals within the fashion business to a more general audience within popular culture who engage with mediated fashion via moving images. Social action thus also referred to how cultural production is woven into a promotional culture of branding and into the fabric of peoples lives, and, as Arvidsson (2006) claims, permeating those life worlds with consumer culture. When consumer culture seamlessly blends with cultural production across a dense network of tastes relating to brands, creative professionals, agencies, contexts, platforms, and formats, the notion of genre ecology enables us to view genre as an emergent, malleable, and dynamic - not merely textual, rule driven or context thick - but also a performative construct fundamentally linked to social and cultural navigation and negotiation of tastes and identities.

\section{REFERENCES}

Arvidsson, A. (2006). Brands. London: Routledge.

Bakhtin, M. (1981). The dialogic imagination. Austin: University of Texas Press.

Barnard, M. (2001). Fashion as communication. (2nd Edn). London: Routledge.

Bateson, G. (1973). Steps to an ecology of mind. London: Paladin.

Berkenkotter, C., \& Huckin, T. (1995). Genre knowledge in disciplinary communication. Hillsdale: Lawrence Erlbaum.

Bordwell, D. (1989). Making Meaning: Inference and rhetoric in the interpretation of cinema. Cambridge: Harvard University Press.

Bruzzi, S. (2000). Grace Kelly. In S. Bruzzi, \& P. Church Gibson (Eds.), Fashion cultures (pp. 205-208). London: Routledge.
Chung, C., Inaba, J., Koolhaas, R., \& Leong, S. (Eds.). The Harvard Design School guide to shopping. Harvard: Graduate School of Design.

Church-Gibson, P. (2012). Fashion and celebrity culture. London: Berg.

Comer-Arldt, E. (2014). It's all about the image: the cooperation between the fashion industry and celebrities. In E. Gaugele. (Ed.), Aesthetic politics of fashion. (pp. 44-59). Berlin: Sternberg Press.

Couldry, N. (2013). Media, society, world. Cambridge: Polity.

Deuze, M. (2007). Convergence culture in the creative industries. International Journal of Cultural Studies, $10(2), 243-263$.

Freadman, A. (2015). The traps and trappings of genre theory. In N. Artemeva \& A. Freedman. (Eds.), Genre studies around the globe: Beyond the three traditions (n.p. Kindle edition). Edmonton: Inkshed Publications.

Freedman, A., \& Medway, P. (Eds.). (1994). Genre and the new rhetoric. London: Taylor \& Francis.

Erickson, T. (2000). Making sense of computer-mediated communication (CMC). Proceedings of 33rd Hawaii International Conference on Systems Science. IEEE Press. DOI: http://dx.doi.org/10.1109/ HICSS.2000.926694 
Fuller, M. (2005). Media Ecologies. Cambridge: The MIT Press.

Gains, J. (2000). On wearing the film: Madam Satan (1930). In S. Bruzzi, \& P. Church.

Gibson. (Eds.), Fashion cultures (pp. 159-190). London: Routledge.

Gaugele, E. (2014). Aesthetic politics in fashion: An introduction. In E. Gaugele. (Ed.). Aesthetic politics of fashion (pp. 11-18.). Berlin: Sternberg Press.

Gauntlett, D. (2015). Making media studies. New York Peter Lang.

Gunning, T. (1990). The cinema of attractions: early film, its spectator and the avant-garde. In T. Elsaesser. (Ed.), Early cinema (pp. 56-61). London: BFI Publishing.

Hartley, J. (2005). Creative industries. Oxford: Blackwell.

Horst, H., Herr-Stephenson, B., \& Robinson, L. (2010). Media ecologies. In M. Ito et al. (Eds), Hanging out, messing around and geeking out (pp. 32-78). Cambridge: The MIT Press.

Hyon, S. (1996). Genre in three traditions: Implications for ESL. TESOL Quarterly, 3O(4), 693-722.

Jenkins, H. (2006). Convergence culture. New York: NYU Press.
Karamoinas, V. \& Geczy, A. (2012). Introduction. In A. Geczy \& V. Karaminas. (Eds), Fashion and art (pp. 177-189). London: Berg.

Karaminas, V. (2012). Image: Fashionscapes. Notes toward an understanding of media technologies and their impact on contemporary fashion imagery. In A. Geczy \& V. Karaminas. (Eds). Fashion and art (pp.113). London: Berg.

Kmais, S., \& Munt, A. (2010). The three Cs of fashion media today: convergence, creativity and control. SCAN Journal of Media Arts Culture, 7(3), http:// scan.net.au/scan/journal/display.php?journal_ $\mathrm{id}=155$. Accessed 19.10.2015).

Khan, N. (2012a). Cutting the fashion body: why the fashion image is no longer still. Fashion Theory, 16(2), 235-250.

Khan, N. (2012b). Stealing the moment: the non-narrative fashion films of Ruth Hogben and Gareth Pugh. Film, Fashion \& Consumption, 1(3), 251-262.

Klingmann, A. (2007). Brandscapes. Cambridge: The MIT Press.

Koolhaas, R., Hommert, J., Kubo, M., \& Office for Metropolitan Architecture. (2001). Prada: Part 1. New York: Distributed Art Publishers.

Kottak, C. (1999). The new ecological anthropology. American Anthropologist, 101(1): 23-35.
Lash, S., \& Lury, C. (2007). Global culture industry. Cambridge: Polity Press

Lemke, J. (1998). Metamedia literacy: transforming meanings and media. In D. Reinking, M. McKenna, L. Labbo, \& R. Kieffer (Eds.), Handbook of literacy and technology (pp. 283-301). Mahwah: Lawrence Erlbaum.

Miller, C. (1984). Genre as social action. Quarterly Journal of Speech, 7o(2), 151-167.

Miller, C. (2015). Genre change and evolution. In N Artemeva \& A. Freedman (Eds.), Genre studies around the globe: Beyond the three traditions (pp. 154-185). Edmonton: Inkshed Publications.

Miller, C. \& Shepherd, D. (2004). Blogging as social action: a genre analysis of the weblog. In L. Gurak, S. Antonijevic, L. Johnson, C. Ratliff, \& J. Reyman (Eds.), Into the Blogosphere. Available: http://blog lib.umn.edu/blogosphere/blogging_as_social_action.html

Mitchell, W.J.T. (2013). Foreword: media aesthetics. In L. Hausken (Ed.), Thinking media aesthetics (pp. 15-27). Frankfurt: Peter Lang.

Morrison, A. (2010). (Ed.), Inside multimodal composition. Cresskill: Hampton Press. 
Morrison, A., \& Skjulstad, S. (2007). Talking cleanly about convergence. In T. Storsul, \& D. Stuedahl (Eds.), The ambivalence of convergence (pp. 217335). Göteborg: Nordicom.

Morrison, A., \& Skjulstad, S. (2010). Mediating hybrid design: imaginative renderings of automotive innovation on the Web. In A. Morrison (Ed.), Inside multimodal composition (pp. 121-144). Cresskill NJ: Hampton Press.

Morrison, A., \& Skjulstad, S. (2011). Laying eggs in other people's pockets. In B. Gentakow, E. Skogseth, \& S. Østerud (Eds.), Literacy - technology - cultural techniques. How does communication technology mediate culture? (pp. 201-224). Cresskill: Hampton Press.

Muriale, S. (2014). From physical to virtual: the global scope of online fashion presentations. In E. Gaugele (Ed.), Aesthetic politics of fashion. (pp. 131-145). Berlin: Sternberg Press.

Prior, P. (2009). From speech genres to mediated multimodal genre systems. In C. Bazerman, A. Bonini, \& D. Figueiredo (Eds.), Genre in a changing world (pp. 17-34). Fort Collins: WAC Clearinghouse and Parlour Press.
Ryan, N. (2007). Prada and the art of patronage. Fashion Theory, 11(1), 7-23.

Skjulstad, S. (2014). 'Exhibiting fashion: museums as myth in contemporary branding and media culture'. In Proceedings of NODEM: Engaging spaces, design and digital strategies (pp. 136-144.) 1-3 December. Warszaw, Poland.

Spinuzzi. C. (2002). Modeling genre ecologies. In Proceedings of the 2oth Annual International Conference on Computer Documentation (SIGDOC '02) (pp. 200-207). ACM: New York.

Spinuzzi, C. (2003). Tracing genres through organizations: A sociocultural approach to information design. Cambridge: The MIT Press.

Spinuzzi, C. \& Zachry, M. (2000). Genre ecologies: an open-system approach to understanding and constructing documentation. ACM Journal of Computer Documentation, 2(3), 169-181.

Strate, L. (2010). Echoes and reflections. Cresskill: Hampton Press.

Swales, J. (2004). Research genres. Cambridge: Cambridge University Press.

Taylor, M. (2005). Culture transition: fashion's cultural dialogue between commerce and art. Fashion Theo$r y, 4(9), 445-460$
Trappel. J. (2015). What to study when studying media and communication innovation? Research design for the digital age. Journal of Media Innovations, 2(1), 7-22. Available: https://www.journals.uio.no/index. php/TJMI/article/view/879

Uhlirova, M. (2013a). 100 years of fashion film: frameworks and histories. Fashion Theory, 17(2), 137-158.

Uhlirova, M. (2013b). The fashion film effect. In D. Bartlett, S. Cole, \& A. Rocamora. (Eds.), Fashion media: Past and present (pp. 118-129). New York Bloomsbury Academic.

von Hippel, E. (1988). The sources of innovation. Oxford: Oxford University Press.

Warner, H. (2012). Critical approaches to on-screen fashion. Film, Fashion \& Consumption, 1(1), 121132. 